\title{
“Tik Tok 出海之路”浅析
}

\section{A Brief Analysis of "Tik Tok's Road to sea" \\ 付屹璇}

YiXuan Fu

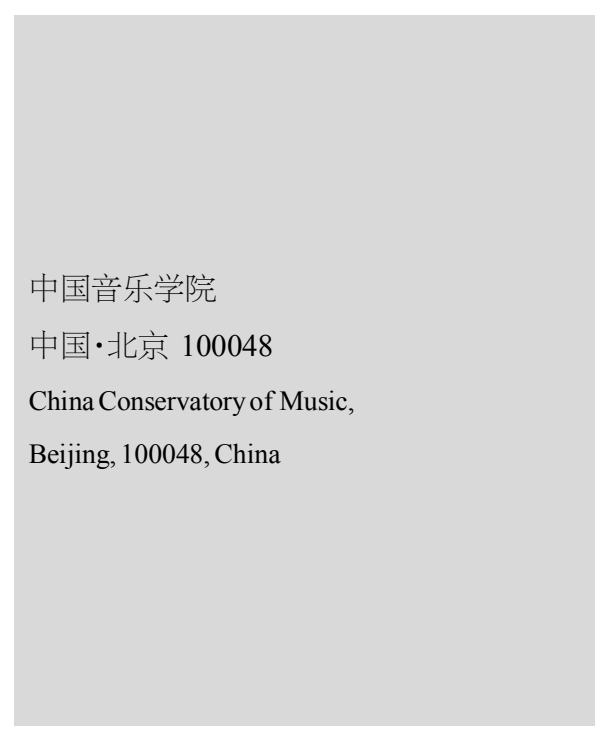

\section{1 引言}

Tik Tok 是字节跳动公司主动走出海外的短视频应用软 件, 是 2017 年由字节跳动花费 10 亿美元收购的音乐短视频 Musical.ly 和中国版抖音相结合的产物。从 Tik Tok 创设以来, Tik Tok 成功进入 15 个国家, 覆盖了 75 种语言。在短视频市 场竞争最为激烈的 2017 年中,Tik Tok 凭借在中国成功运营 的经验走入美国市场。Tik Tok 从中国走出去的成功原因正是 得益于其内容营销的方式与手段。无论从播主的管理与运营 还是用户的体验与维系都是值得借鉴与学习的。

\section{2 抖音发展现状}

Tik Tok (抖音国际版)的 1 岁之路在海外虽然艰难但总 体势好。依据 Sensor Tower, 在 2019 年第一季度, 非游戏应用 程序的下载量排名 Tik Tok 位居第三, 营收 1.88 亿美元, 同比 增长 $70 \%$, 其中在印度地区增长最为明显, 共有 8860 万用户 加入; 美国地区有 1320 万用户加人, 同比增长 181\%。Tik Tok 的安装量突破 8 亿次。2019 年第一季度全球营收额超 1890 万美元,比 2018 年第一季度增长 $222 \%$ 。

\section{3 环境分析}

\section{1 国际短视频 app 行业环境分析}

近几年来, 中东地区不断成为短视频厂商关注的区域,也
为短视频的发展提供了平台和资源。2018 年年中, 中东前 20 强视频和直播应用程序中有 15 个是中国应用程序,其中 3 个 在美国, 1 个在俄罗斯, 1 个在澳大利亚 ${ }^{[1]}$ 。在 2018 年的下载列 表中, 中东地区的采用商店和 Google Play 共收到 9700 万次 下载, 其中仅中国采用就有 9075 万次, 占 $93 \%$ 。由此可见中 国短视频在中东市场中已处于领先地位并保持高速的势头前 进。据称“国际短视频的前进取决于中国, 中国网络视频的前 进取决于美国”。依据 Sensor Tower 报告, 春季美国四大社交应 用程序总下载量在 apple store 和 Google Play 获得 3.76 亿, 年 均增长率为 $3.1 \%$ 。随着智能手机在世界范围内的普及和发展 中国家社交媒体的前进,全球社交媒体用户的数目继续增长。 预计 2019 年全球社交媒体使用者将达到 28.9 亿。

\section{2 市场环境 SWOT 分析}

优势：(1)短视频行业逐渐规范化并且保持稳定增长的利 好环境。(2)国家对网络技术的重视程度逐渐增加, 坚持长远、 可持续的发展观点。(3)抖音中国日活跃突破 2 亿, 其在中国的 成功运营为 Tik Tok 出海奠定了扎实的基础。(4)Tik Tok 具备 母公司管理科学且独到的管理理念。(5Tik Tok 具有强大且体 系化的营销模式。

劣势: (1)欧美市场对传统老牌社交媒体的重视程度较高, 但由于国家间政治与经济关系,相关政策变化极大,目前看来 并不势好。(2)Tik Tok 虽取胜于内容产品但其在技术上的创新 度和领先型并不够。 (3)由于 PGC 的特点使其内容的审查与监 


\section{国际经济 International Economy}

管更为复杂, 难度更大。(4)相比传统媒体, Tik Tok 投放渠道和 流程更为复杂, 在海量资源中匹配合适内容和精力成本过高。

机会：(1)智能手机与互联网的迅速发展使国际短视频发 展势头强劲，海外市场成功拓展会为其全球化发展提供更大 的空间和机会。2国际市场中曾出现类似的热门短视频应用 需要单用户具备高水平的专业技能才能创作出吸引人的视 频, 而 Tik Tok 编辑功能简单, 给原创视频更多的空间, 国际 用户的需求也是其扩展规模的机遇。(3Tik Tok 在中国成熟的 运营经验以及在海外良好发展的基础上，具有创造力的营销 管理团队为其发展带来更多可能。

威胁: (1)欧美龙头社交应用 Facebook 于 2018 年初推出 与 Tik Tok 相似度极高的 app 名为 Lasso, 试图运用其在市场 惯用的复制手段对 Tik Tok 进行压制。2)国际进人壁垒较大， Tik Tok 出海面临各国的阻碍与威胁。

\section{4 市场运营与营销分析}

\section{1 定位}

从 Tik Tok 的 slogen “专注新生代的音乐短视频社区” 以 及视频时长限制在 5-15s 的规定可以看出, Tik Tok 的定位是 年轻人的音乐短视频社区, 提倡做垂直音乐的 UGC 短视频, 其出海战术也坚定铁打的产品形式一一本土化的内容。其目 标用户可分为三类: KOL 用户 (内容生产者); 追随型用户(内 容次生产者),汶览型用户(内容消费者)是前两种类型用户的 群众基础。

\section{2 内容及产品组织}

从内容层级结构来看, Tik Tok 的一级内容包括: 首页、发 现、制作、消息和我。其内容结构划分合理,核心功能均位于醒 目位置。

\section{3 内容运营方式}

Tik Tok 为了保证其视频内容的分发效率以及去中心化, 在产品推广中使用了算法推荐模型。Tik-Tok 为 UGC 和 PGC 内容产品制定了基本标准。在政治态度上, 反对“违反法律法 规、损害国家和社会安全的内容”、反对“不利于他人的内容”、 反对“消极内容”和“虚假夸大内容”; 在内容范围, 反对“可能 导致违规的内容”、反对“重复相像的内容”、反对“不合乎短视 频形式的内容。这些根基标准为官方审查团体和公共编辑团 体筛查各种 UGC 和 PGC 内容提供了保障, 维护了 Tik Tok “高质量内容社区”的口碑。

\section{4 运营策略( 内容营销模式)}

(1)细分切人市场及明星冷启动。产品开始投放市场的阶 段中,抖音没有采取任何大手笔的宣传和推广手段,仅仅凭借
抖音产品在市场中的效果引起社会注意。

(2)线上+线下推广 $=$ 新用户拓展。借助明星造势的 KOL 模 式只是让用户认识到自己的第一步, 要把产品推到火爆, 让更 多人知道这个产品, 从而发挥更大的影响力, 就需要更完善的 营销链即线上+线下推广与活动 ${ }^{[2]}$ 。

(3)流失用户召回。Tik Tok 的运营目标在于获取大量新用 户，实际上 Tik Tok 的召回手段就是将自己经常暴露在人的 视线中。当然 Tik Tok 也不停的更新版本, 每一次特性都是一 次很好的用户召回。

(4)全球化产品, 本土化内容。Tik Tok 出海最大的成功之 处在于其 “不变与变”的运营方式即铁打的产品和本土化的内 容。Tik Tok 提供各种技术与渠道的支持, 帮助他们实现更大 流量与变现。

(5)广告投放与流量变现。Tik Tok 采用的广告投放方式共 有三种,其一开屏广告; 其二信息流广告; 其三 Tik Tok 挑战 赛主力品牌用原生沉浸的方式传递信息, 并激发品牌与 UGC 用户互动, 用高质量的内容缩短营销链路刺激用户共鸣。

\section{5 出海坎坷与反思}

Tik Tok 在海外的迅速发展实际上也遭到了众多国家的排 不。2018 年 7 月 3 日印尼政府下令封禁 Tik Tok, 并称 Tik Tok 为获取流量上传令人不适的视频内容, 如“青少年坟头蹦迪”等; 2018 年 7 月 30 日马来西亚军方通过官方 Facebook 账号发帖 禁止现役军人穿着军装在 Tik Tok 上发布短视频并要求政府 严管 Tik Tok 等等事件。这款爆火的现象级 app 遭遇诸多坎坷 引发我们深思, 在其成功的市场运作同时应该更加注意其产品 的核心, 把控即内容与用户的监管。为此提出两点建议。

\section{1 建立用户激励体系}

首先通过用户分类明确用户成长路径，在其养成期间发 掘并强化其差异性, 通过礼品和优惠券等物质或红人认证、参 与挑战赛等进行激励, 或者创建更多的视频模版及特效的功 能, 并建立及时、排余畏难与不确定性的激励原则。

\section{2 完善用户与内容监管}

一方面通过用户激励体系在素人培养全过程上进行把 控, 另一方面完善 Tik Tok 后台对用户上传视频审核的机制, 建立专门的反馈控制小组,注重收集并研究市场反应等。

\section{参考文献}

[1]吴佳妮.音乐社交短视频软件何以走红一以抖音 App 为例 [J].新媒体研究,2017(18):88-89.

[2]杨乐怡. 重新崛起:短视频行业的 UGC 价值再现一以快手 为例 $[J]$.新闻战线,2017(10):107-109. 